\title{
Disorders of the lower cranial nerves
}

\author{
Josef Finsterer, Wolfgang Grisold ${ }^{1}$ \\ Krankenanstalt Rudolfstiftung, 'Department of Neurology, Kaiser-Franz-Josef Spital, Vienna, Austria, Europe
}

\begin{abstract}
Lesions of the lower cranial nerves $(\mathrm{LCN})$ are due to numerous causes, which need to be differentiated to optimize management and outcome. This review aims at summarizing and discussing diseases affecting LCN. Review of publications dealing with disorders of the LCN in humans. Affection of multiple LCN is much more frequent than the affection of a single LCN. LCN may be affected solely or together with more proximal cranial nerves, with central nervous system disease, or with nonneurological disorders. LCN lesions have to be suspected if there are typical symptoms or signs attributable to a LCN. Causes of LCN lesions can be classified as genetic, vascular, traumatic, iatrogenic, infectious, immunologic, metabolic, nutritional, degenerative, or neoplastic. Treatment of LCN lesions depends on the underlying cause. An effective treatment is available in the majority of the cases, but a prerequisite for complete recovery is the prompt and correct diagnosis. LCN lesions need to be considered in case of disturbed speech, swallowing, coughing, deglutition, sensory functions, taste, or autonomic functions, neuralgic pain, dysphagia, head, pharyngeal, or neck pain, cardiac or gastrointestinal compromise, or weakness of the trapezius, sternocleidomastoid, or the tongue muscles. To correctly assess manifestations of LCN lesions, precise knowledge of the anatomy and physiology of the area is required.
\end{abstract}

Key words: Accessory, cranial nerves, glossopharyngeal, hypoglossal, infection, neoplasm, trauma, vagus, vascular

\section{Introduction}

Lower cranial nerves (LCN) include the paired $9^{\text {th }}$ (glossopharyngeal), $10^{\text {th }}$ (vagal), $11^{\text {th }}$ (accessory) and $12^{\text {th }}$ (hypoglossal) cranial nerves. ${ }^{[1]}$ Particularly the $9^{\text {th }}$, $10^{\text {th }}$, and $12^{\text {th }}$ cranial nerves are involved in the execution of crucial physiological functions, such as swallowing, tasting, speech, heart rate and blood pressure control, and peristalsis. In addition to motor fibers, LCN carry sensory fibers and autonomic fibers. LCN are affected in a number of pathologic conditions. This review aims at summarizing and discussing diseases associated with LCN, its diagnosis, treatment, and outcome. Due to limitations in space, synaptic and postsynaptic neuromuscular transmission disease and disorders of the skeletal muscles supplied by LCN were excluded, and the discussion about treatment and outcome limited.

\begin{tabular}{|l|l|}
\hline \multicolumn{2}{|c|}{ Access this article online } \\
\hline Quick Response Code: & Website: \\
\hline & www.ruralneuropractice.com \\
\cline { 2 - 3 } & \\
\hline
\end{tabular}

\section{Methods}

Data for this review were identified by searches of MEDLINE, Current Contents, PubMed, and references from relevant articles using the search terms "glossopharyngeal nerve," "vagal nerve," "accessory nerve," "hypoglossal nerve," and "cranial nerves," in combination with "genetic," "hereditary," "motor neuron disease," "stroke," "vascular," "vasculitis," "trauma," "head injury," "iatrogenic," "infections," "immunologic," "immune neuropathies," "multiple sclerosis," "diabetes," "vitamin deficiency," "degeneration," "malformation," "neoplasm," and "carcinoma." Randomized (blinded or open-label) clinical trials, longitudinal studies, case series, and case reports were considered. Abstracts and reports from meetings were not included. Only articles published in English between 1966 and 2014 were considered. Appropriate papers were studied and discussed for their suitability to be incorporated in this review.

\section{Anatomy and Physiology of Lower Cranial Nerves}

To understand the complicated interplay between the four LCN and their anatomy and various functions,

Address for correspondence:

Dr. Josef Finsterer, Postfach 20, 1180 Vienna, Austria, Europe. E-mail: fifigs1@yahoo.de 
it is essential to realize the basics of anatomy and physiology.

\section{$9^{\text {th }}$ cranial (glossopharyngeal) nerve}

The ninth cranial nerve is a mixed nerve carrying motor efferents and sensory afferents. The nerve mediates five distinct functions: A branchial motor function providing voluntary control of the stylopharyngeal muscle (dilates and elevates pharynx during swallowing and speech); visceral motor functions to innervate the parotid gland via preganglionic fibers to the otic ganglion and postganglionic fibers to the parotid gland; visceral sensory functions providing visceral sensory input from the carotid sinus and carotid bodies, general somatic afferent functions providing sensory information for the skin of the external ear, the internal surface of the tympanic membrane, the upper pharynx, the soft palate, the tonsils, and the posterior third of the tongue; and a special sensory function providing taste sensation from the posterior third of the tongue..$^{[2]}$ Branches of the nerve include the tympanic, the pharyngeal, the lingual, the sinus caroticus, the tonsillar, and the stylopharyngeal branch. There is also a communicating branch to the vagal nerve..$^{[2]}$

The branchial motor branch originates from the nucleus ambiguus in the reticular formation of the medulla, emerges from the lateral aspect of the medulla, exits the skull via the jugular foramen, and descends to the styloid process to innervate the target muscles. ${ }^{[3]}$ The visceral (parasympathetic) motor branch of the nerve innervates the ipsilateral parotid gland. Preganglionic fibers originate from the inferior salivatory nucleus (receives afferents from the hypothalamus and the olfactory system) to exit the medulla between olive and inferior cerebellar peduncle. Together with other components of the nerve, parasympathetic fibers cross the two glossopharyngeal ganglia in the jugular foramen to form the tympanic nerve. The tympanic nerve ascends into the tympanic cavity to form a plexus, which provides the general sensation of the middle ear. Parasympathetic fibers leave the plexus as the lesser petrosal nerve, re-enter the middle cranial fossa to exit the skull via the foramen ovale along with the mandibular nerve and synapses in the otic ganglion. Postganglionic fibers travel with the auriculo-temporal branch of the mandibular nerve to enter the parotid gland. The visceral sensory component carries impulses from the baroreceptors of the carotid sinus and the chemoreceptors of the carotid body via the sinus nerve to join the $9^{\text {th }}$ cranial nerve at the inferior glossopharyngeal ganglion. From there these projections reach the tractus solitarius to synapse in the caudal nucleus solitarius. Connections are made with the reticular formation and the hypothalamus to mediate cardiovascular and respiratory reflex responses to changes of blood pressure or $\mathrm{CO}_{2} / \mathrm{O}_{2}$. The general sensory component originates from the skin of the external ear, the upper pharynx, and the posterior third of the tongue to travel via the pharyngeal branch and the tympanic nerve to the spinal trigeminal tract. Ascending neurons project to the thalamus. These sensory fibers mediate the afferent limb of the gag reflex, while the efferent impulse is carried by the branchial motor fibers of the vagal nerve. The $9^{\text {th }}$ cranial nerve is also involved in the afferent side of the cough reflex. ${ }^{[4]}$ Special sensory fibers carry taste sensation from the posterior third of the tongue to the inferior ganglion, and then pass the jugular foramen to ascend to the tractus solitarius and synapse with the nucleus solitarius..$^{[1,2]}$ Hiccups are due to a brief contraction of the inspiratory muscles plus a glottis adduction of the stylopharyngeal muscles. ${ }^{[4]}$

\section{$10^{\text {th }}$ cranial (vagal) nerve}

The vagal nerve is a mixed nerve carrying motor efferents and sensory afferents. The nerve conducts five distinct qualities, which are carried along general visceral efferent fibers (parasympathetic innervation of pharyngeal, laryngeal, bronchial, and gastrointestinal mucosa), general visceral afferent fibers (sensory information from the thoracic and abdominal viscera, the aortic body, aortic arch), special visceral afferent fibers (carry taste of the epiglottal region), general somatic afferent fibers (carry sensation from the external auditory meatus, outer tympanic membrane, back of the ear, part of meninges, pharynx), and along special visceral efferent fibers, which innervate skeletal muscles of the pharynx and larynx. Skeletal muscles innervated by the vagal nerve include the cricothyroid, levator veli palatini, salpingopharyngeus, palatoglossal, palatopharyngeus pharyngeal constrictor, and the laryngeal muscles (except cricothyroid). Innervation of these muscles is involved during speech or opening of the larynx during breathing. Efferent parasympathetic fibers control heart rate, peristalsis, and sweating. Stimulation of the efferent parasympathetic fibers lowers heart rate or blood pressure. $80-90 \%$ of the vagal fibers are afferent, only $10-20 \%$ are efferent fibers. ${ }^{[5]}$

Vagal nerve fibers originate from or converge to four medullar nuclei, which include the dorsal nucleus of the vagal nerve (responsible for parasympathetic output to viscera), nucleus ambiguus (origin of branchial efferent motor fibers and of preganglionic parasympathetic to the heart), solitary nucleus (receives taste information and afferents from viscera), and the spinal trigeminal nucleus (receives sensory input from the outer ear, dura, posterior cranial fossa, and mucosa). The vagal nerve leaves the medulla between the pyramid and 
inferior cerebellar peduncle, crosses the jugular foramen, and passes into the carotid sheath down to the neck, chest and abdomen. It splits into the auricular, pharyngeal (innervates palate and pharynx), superior laryngeal (innervates constrictor and cricothyroid), and recurrent laryngeal nerves, the anterior and posterior vagal trunk, and provides superior and inferior cervical cardiac branches and thoracic cardiac branches to the heart and the esophageal and pulmonary plexus (vagus nerve branches). The superior laryngeal nerve divides into the internal and external laryngeal nerves. The external laryngeal branch supplies the inferior constrictors. The vocal cord is also innervated by the superior laryngeal nerve and the external and internal rami of the inferior laryngeal nerve. ${ }^{[5]}$

The right vagus crosses anteriorly of the subclavian artery, runs posterior of the superior vena cava, descends posterior to the right main bronchus to form the cardiac, pulmonary and esophageal plexus. Distally, the right vagal nerve passes over into the posterior vagal trunk, which crosses the diaphragm through the esophageal hiatus. The right recurrent laryngeal nerve deviates from the right vagal nerve and hooks around the right subclavian artery and ascends to the neck. From the left vagal nerve deviates the left recurrent laryngeal nerve, which hooks around the aortic arch to ascend back to the neck. After having contributed to the esophageal, cardiac, and pulmonary plexus, the left vagal nerve forms the anterior vagal trunk, which enters the abdomen via the esophageal hiatus. The right vagal nerve innervates the sinusnode, whereas the left vagal nerve innervates the atrioventricular-node. One of the most important reflexes mediated by the vagal nerve is the gag reflex. Also, the cough reflex is partially mediated via general visceral afferent parasympathetic fibers. ${ }^{[4]}$ The cough reflex is initiated by cough receptors. Vagal sensory fibers together with trigeminal and glossopharyngeal fibers carry information from the cough receptors to the cerebral cough center (nucleus tractus solitarius). From there efferent fibers of the phrenic nerve, spinal nerves, and laryngeus recurrens nerve project to the diaphragm, abdominal, intercostal, and laryngeal muscles. ${ }^{[4]}$ Parasympathetic compensation of sympathetic overstimulation in response to pain, carotid sinus massage, the Valsalva manoeuvre, or gastrointestinal illness, may cause a vasovagal syncope.

\section{$11^{\text {th }}$ cranial (accessory) nerve}

The accessory nerve is anatomically split into a spinal and a cranial portion. Fibers of the spinal portion originate from the upper spinal cord (spinal accessory nucleus located in the postero-lateral aspect of the anterior horn). The cranial portion originates from the nucleus ambiguus, which is continuous with the lateral horn of the cervical segments. The spinal roots form the spinal accessory component, which enters the skull through the foramen magnum. The cranial part descends from the medulla oblongata to connect with the spinal accessory component. The nerve then courses along the skull to the jugular foramen through which it exits together with the $9^{\text {th }}$ and $10^{\text {th }}$ cranial nerve. The $10^{\text {th }}$ cranial nerve lies most medial in the foramen. The $9^{\text {th }}$ cranial nerve exits together with the inferior petrosal sinus through the anterior compartment of the foramen. Vagus and accessory nerves exit via the middle compartment of the foramen. The sigmoid sinus exits via the posterior compartment of the foramen. Shortly before crossing the foramen, the cranial component branches off the accessory nerve to join the vagal nerve (the $11^{\text {th }}$ cranial nerve is a transitional nerve). In the neck, the nerve crosses the internal jugular vein anteriorly ( $80 \%$ of cases) or posteriorly $(20 \%$ of cases) to enter the target muscles shortly afterwards. Due to this unique anatomic course, the accessory nerve is the only cranial nerve which enters and exits the skull and is thus sometimes not regarded as a true cranial nerve. ${ }^{[6]}$ Physiologically, the accessory nerve is a mixed or transitional nerve conducting general somatic qualities (innervation of the sternocleidomastoid and trapezius muscles) originating from the cranial portion and a distinct modality originating from the spinal portion. ${ }^{[7]}$ Anastomoses between the spinal component of the accessory nerve and the dorsal roots of the cervical nerves exist below level C1. ${ }^{[8,9]}$

\section{$12^{\text {th }}$ cranial (hypoglossal) nerve}

The hypoglossal nerve innervates the muscles of the tongue and is involved in tongue movements during speech, food manipulation, and swallowing. ${ }^{[1]}$ The nerve is pure motor. ${ }^{[10]}$ The nerve directs not only voluntary activities of the tongue, but also involuntary functions, such as clearing the mouth of saliva by swallowing. The nerve is also involved in adjusting the tongue to new movements to create desired sounds when learning a new language. ${ }^{[10]}$ The nerve originates from the hypoglossal nucleus. ${ }^{[1]}$ It leaves the medulla oblongata between the olive and the pyramid to pass through the hypoglossal canal. Immediately after leaving the skull it gives off a meningeal branch and unites with a branch of the anterior root $\mathrm{C} 1$, which innervates the geniothyroid and thyrohyoid muscles. The nerve then winds behind the $10^{\text {th }}$ cranial nerve and passes between internal carotid artery and internal jugular vein to the posterior belly of the digastric muscle to continue to the submandibular region lateral to the hypoglossal muscle and inferior of the lingual nerve to finally reach the tongue. All muscles of the tongue are supplied except for the palatoglossal muscle, which is innervated by the $9^{\text {th }}$ cranial nerve. 
There are anastomoses between the hypoglossal nerve and other caudal cranial nerves and the cervical plexus.

\section{Classification of Lower Cranial Nerve Lesions}

Lesions of the LCN may be classified according to various aspects. According to the number of nerves affected they may be categorized as either single nerve lesions or as multiple nerve lesions. According to the impaired function, they may be qualified as motor (muscle or visceral) or sensory (visceral, general somatic, special). LCN lesions may be also classified whether the nerves are involved individually or whether other cranial nerves, the brain, the spinal cord or the spinal nerves are additionally affected. Another categorization is based on the cause of the lesion, which may be genetic, vascular, traumatic, iatrogenic, infectious, immunologic, metabolic, nutritional, degenerative, or neoplastic.

\section{Symptoms of Lower Cranial Nerve Lesions}

Symptoms arising from lesions of LCN correlate with the various functions of the four nerves. Thus, symptoms of LCN lesions include dysphagia, dysarthria, hoarse voice, chocking during ingestion of fluids, taste disturbances (posterior third of tongue), sensory disturbances (posterior third of the tongue, soft palate, throat, external auditory meatus), palpitations, tachycardia, bradycardia, tachypnea, bradypnea, dyspnea, arterial hypotension, arterial hypertension, fainting, syncope, dizziness, pain in the posterior oral cavity, the face, the neck, the head, obstipation, or diarrhoea. Affection of the $11^{\text {th }}$ cranial nerve may lead to weakness of head rotation, head anteflexion, or shoulder elevation, to scapular winging or to shoulder pain. Affection of the $12^{\text {th }}$ cranial nerve may lead to slurring of speech and the feeling of a thick, heavy, or clumsy tongue. If additional neural or nonneural structures are involved, symptomatology may be even broader.

Affection of the LCN may go along with pain, such as neuralgias, dysesthesias, paresthesias, muscle pain, or pain with swallowing. Neuralgias are characterized by paroxysmal painful attacks of electric shock-like sensation, occurring spontaneously or evoked by innocuous stimuli in specific trigger areas. ${ }^{[11]}$ Pain is usually experienced in the distribution of one or several nerves. Neuralgias of the LCN are the rare glossopharyngeal neuralgia and the even more rare neuralgia of the laryngeal nerve. Glossopharyngeal neuralgia is characterized by excruciating pain attacks of the short duration of the ear, pharynx, neck, tonsil, or base of the tongue. Pain may be triggered by contact of the tongue with the teeth ${ }^{[12]}$ or with the back of the tongue. ${ }^{[13]}$ Glossopharyngeal neuralgia may be associated with syncope (fainting) in 10\% of the cases due to reflex bradycardia (efferent limb of reflex via vagal nerve) or occasionally induced by swallowing. Glossopharyngeal neuralgia is most frequently primary (compression of the nerve by adjacent vessel loop ${ }^{[14]}$ or secondary to an intrinsic brain lesion such as in multiple sclerosis ${ }^{[13,15]}$ or in the Eagle-syndrome. ${ }^{[16]}$ Neuralgia of the laryngeal nerve is a rare condition and may be due to a deviated hyoid bone, ${ }^{[17]}$ due to previous acute laryngitis, ${ }^{[18]}$ a pharyngeal diverticulum, ${ }^{[19]}$ or idiopathic. ${ }^{[20]}$ Patients present with paroxysmal, lancing pain located to the area of the thyrohyoid membrane, which can be induced or worsened by swallowing. ${ }^{[17]}$

\section{Investigations to Diagnose Lower Cranial Nerve Lesions}

\section{Clinical exam (signs of lower cranial nerve lesions) Neurological}

Examination of the $9^{\text {th }}$ cranial nerve includes asking the patient to swallow or cough. In addition, taste and a general sensation of the posterior third of the tongue and the throat can be evaluated. The bitter taste (posterior third of the tongue) is used to test for this nerve. There may also be hypoesthesia of the soft palate or reduced palatal or pharyngeal reflexes. Physical exam of the $10^{\text {th }}$ cranial nerve includes eliciting the gag reflex, to look if the uvula is deviated from the side of the lesion, if there is failure of palate elevation upon phonation, and evaluation of speech impairment. In case of bilateral vagal nerve lesions, heart rate and breath rate may be increased. The somatic sensory function can be assessed by testing the sensibility of the external auditory meatus. The $11^{\text {th }}$ cranial nerve is tested by assessing strength, mass, and spontaneous activity of the trapezius and sternocleidomastoid muscle. The patient is asked to shrug the shoulders with and without resistance. The sternocleidomastoid is tested by asking the patient to turn the head to the left or right or to anteflect the head against resistance. Inspection of the muscles may reveal wasting or fasciculations. The $12^{\text {th }}$ cranial nerve is tested by asking the patient to stick the tongue out straight. If there is a lesion of the nerve, the tongue will deviate toward the affected side or there may be wasting and fasciculations if the lesion is not acute. The strength of the tongue can be tested by pressing it toward the cheek against the finger of the examiner outside. Weakness of the tongue will also manifest as slurred speech. Practical bedside testing is used to identify lesions in the anterior part of the oral 
cavity (" $\mathrm{B}$ "), the oral cavity in particular the tongue (" $\mathrm{T}$ ") and the posterior part of the oral cavity ("G").

Lower cranial nerve lesions may occur in particular distributions giving rise to various syndromes, such as Horner-syndrome, Tapia-syndrome, Collet-Sicardsyndrome, Vernet-syndrome, Jugular-foramensyndrome, Garcin-syndrome, Schmidt-syndrome, or Villaret's-syndrome [Table 1]. These syndromes are usually case-based descriptions, which are useful, to summarize, the findings, but usually lack accuracy. ${ }^{[21-24]}$ Vernet-syndrome manifests with dysphonia, hoarseness, drop of soft palate, deviation of the uvula, dysphagia, hypoesthesia of the posterior third of the tongue, reduced parotid gland secretion, loss of gag reflex, and weakness of the sternocleidomastoid and trapezius muscles. Jugular-foramen-syndrome is characterized by acute onset dysphagia, dysphonia, and accompanied or preceded by cranial, cervical, or pharyngeal pain. ${ }^{[2]}$ The most frequent cause of jugular-foramen-syndrome is herpes zoster oticus with herpetic eruptions of the skin or the mucosa. Magnetic resonance imaging (MRI) may reveal contrast enhancement around the jugular foramen, suggesting inflammation of the glossopharyngeal or vagal nerve ganglia. ${ }^{[25]}$ Imaging may also show erosions of bones or metastasis. The diagnosis is confirmed by demonstration of varicella-zoster virus (VZV)-DNA or VZV antibodies in the cerebro-spinal fluid (CSF). ${ }^{[25]}$

\section{Oto-rhino-laryngological}

Clinical exam by the oto-rhino-laryngologist may be helpful to detect oto-rhino-laryngological causes of LCN lesions. The oto-rhino-laryngologist may assess morphology and function of the oral cavity and the larynx.

\section{Table 1: Syndromes of lower cranial nerve lesions}

\begin{tabular}{ll}
\hline Syndrome & Definition \\
\hline Tapia-syndrome & Hypoglossal nerve palsy and deficit of the laryng \\
& branch of the vagal nerve resulting in unilateral ton \\
& palsy and unilateral vocal cord palsy \\
Collet-Sicard-syndrome & Palsy of the $9^{\text {th }}, 10^{\text {th }}, 11^{\text {th }}$, and $12^{\text {th }}$ cranial nerve
\end{tabular}

Vernet-syndrome

Palsy of the $9^{\text {th }}, 10^{\text {th }}$ and $11^{\text {th }}$ cranial nerve

Jugular-foramen-syndrome

Schmidt-syndrome

Villaret's-syndrome

Wallenberg-syndrome

Avellis-syndrome

Jackson-syndrome

Opalski-syndrome

Cestan-Chenais syndrome

Dejerine syndrome

Garcin-syndrome
Acute onset dysphagia, dysphonia, accompanied or preceded by cranial, cervical, or pharyngeal pain, due to affection of the $9^{\text {th }}, 10^{\text {th }}$, and $11^{\text {th }}$ cranial nerve Ipsilateral palsy of the $9^{\text {th }}, 10^{\text {th }}, 11^{\text {th }}$, and $12^{\text {th }}$ cranial nerves with contralateral hemiparesis

Unilateral palsy of $9^{\text {th }}, 10^{\text {th }}, 11^{\text {th }}$, and $12^{\text {th }}$ nerve and ipsilateral Horner's sign

Lateral medullary syndrome (dysphagia, slurred speech, vertigo, double vision, palatal myoclonus, ipsilateral ataxia, hemifacial hypesthesia, nystagmus, Hornersyndrome, vocal cord paresis+contralateral impairment of pain, temperature, and lemniscal sensation, lateropulsion to side of lesion)

Ipsilateral paralysis of soft palate and vocal cord+contralateral loss pain and temperature sensation Ipsilateral hypoglossal palsy and contralateral hemiparesis Ipsilateral hemiparesis, lemniscal sensation loss, hypoglossus nerve palsy

Contralateral hemiplegia, hemihypesthesia, paralysis of the larynx and soft palate, and Horner-syndrome

Ipsilateral hypoglossal palsy, contralateral hemiplegia and loss of proprioception

Unilateral palsy of cranial nerves 5-12 or all cranial nerves

\section{Causes}

Anterior or posterior cervical spine surgery, airway manipulation, cervical laminoplasty, trauma during bullfights, or inflammatory pseudotumor of the neck

Glomus tumor jugulotympanicum, base of skull metastasis, neck fibrosarcoma, multiple myeloma, hypoglossal Schwannoma, jugular foramen neurinoma, jugular foramen metastatic melanoma, hemangiopericytoma, carotid or vertebral artery dissection, panarteritis nodosa, closed head trauma, necrotising otitis externa, occipital condyle fracture, traumatic atlas fracture, skullbased osteomyelitis, sinus thrombosis, carotid fibromuscular dysplasia, pseudoaneurysm of maxillary artery, cardiac surgery, Jefferson fracture Malignancy, aneurysm, zoster meningitis, osteolytic metastasis of the petrous pyramid, or base of the skull fracture

Herpes zoster oticus

Stroke, multiple sclerosis

Carotid artery dissection, local metastasis

Stroke

Stroke

Stroke

Stroke

Stroke, multiple sclerosis, tumor

Occlusion of anterior spinal artery

Base of the skull inflammation, neoplasm, base of the skull metastasis 


\section{Instrumental investigations}

Most helpful in the work-up of LCN lesions is the application of static or dynamic imaging methods, such as X-ray (base of the skull, styloid process, deglutition), video-cinematography (dynamic), computed tomography, MRI, angiography (static), or ultrasound [Figure 1]. A useful tool to investigate lesions of the tongue is an ultrasound. Muscle MRI may show atrophy as an indirect sign of a lesion of the supplying nerve by bone erosion or metastases. Oto-rhino-laryngological techniques, such as fiber-optic endoscopy can be helpful to detect causes of LCN lesions. Electrophysiological techniques, such as nerve conduction studies, ${ }^{[26]}$ electromyography (larynx muscles (cricothyroid, thyroarytenoid muscles), sternocleidomastoid, trapezius muscles), electrical nerve root stimulation, or trans-cranial magnetic stimulation (accessory, hypoglossal nerve) are helpful for localizing the level of a nerve lesion and to determine whether it is axonal or demyelinating in nature. Intra-operative electrophysiological monitoring of LCN functions can be helpful to avoid iatrogenic damage of the LCN during surgery. Blood chemistry can be useful to assess inflammatory markers, antibodies against viruses, vasculitis parameters, vitamin levels, tumor-markers, etc. CSF investigations may be helpful to detect infections (meningitis), neoplastic (carcinosis), or immunologic disease (radiculitis) as a cause of LCN lesions. To assess parasympathetic functions autonomic testing by means of the Valsalva maneuver, heart rate variability, tilt test, gastric emptying tests, the sympathetic skin response, the quantitative sudomotor axon reflex test, or the thermoregulatory sweat test is available.

\section{Disorders of Lower Cranial Nerves}

Isolated affection of a single cranial nerve is rare [Table 2]. In the majority of the cases, multiple $\mathrm{LCN}$ are simultaneously affected. Causes of LCN lesions can be genetic, vascular, traumatic, iatrogenic, infections, immunologic, metabolic, nutritional, degenerative, or neoplastic.

\section{Genetic causes}

The most frequent genetic disorders associated with LCN involvement are the motor neuron disorders (MNDs). They include amyotrophic lateral sclerosis (ALS), spinal muscular atrophy, bulbospinal muscular atrophy (BSMA), and unclassified MNDs (Sandhoff disease, triple-A-syndrome, Brown-Vialetto-Van Lare-syndrome). Among these, LCN are affected in ALS, BSMA, triple-A-syndrome, and Brown-Vialetto-Van Lare-syndrome. More rarely, cranial nerves are involved in hereditary neuropathy.

\section{Amyotrophic lateral sclerosis}

Amyotrophic lateral sclerosis is the most common among the MNDs. ${ }^{[27-29]}$ ALS is sporadic in the majority of the cases but hereditary in an increasing number of patients with sporadic ALS. ${ }^{[29]}$ More details are thus presented in the chapter about degenerative causes.

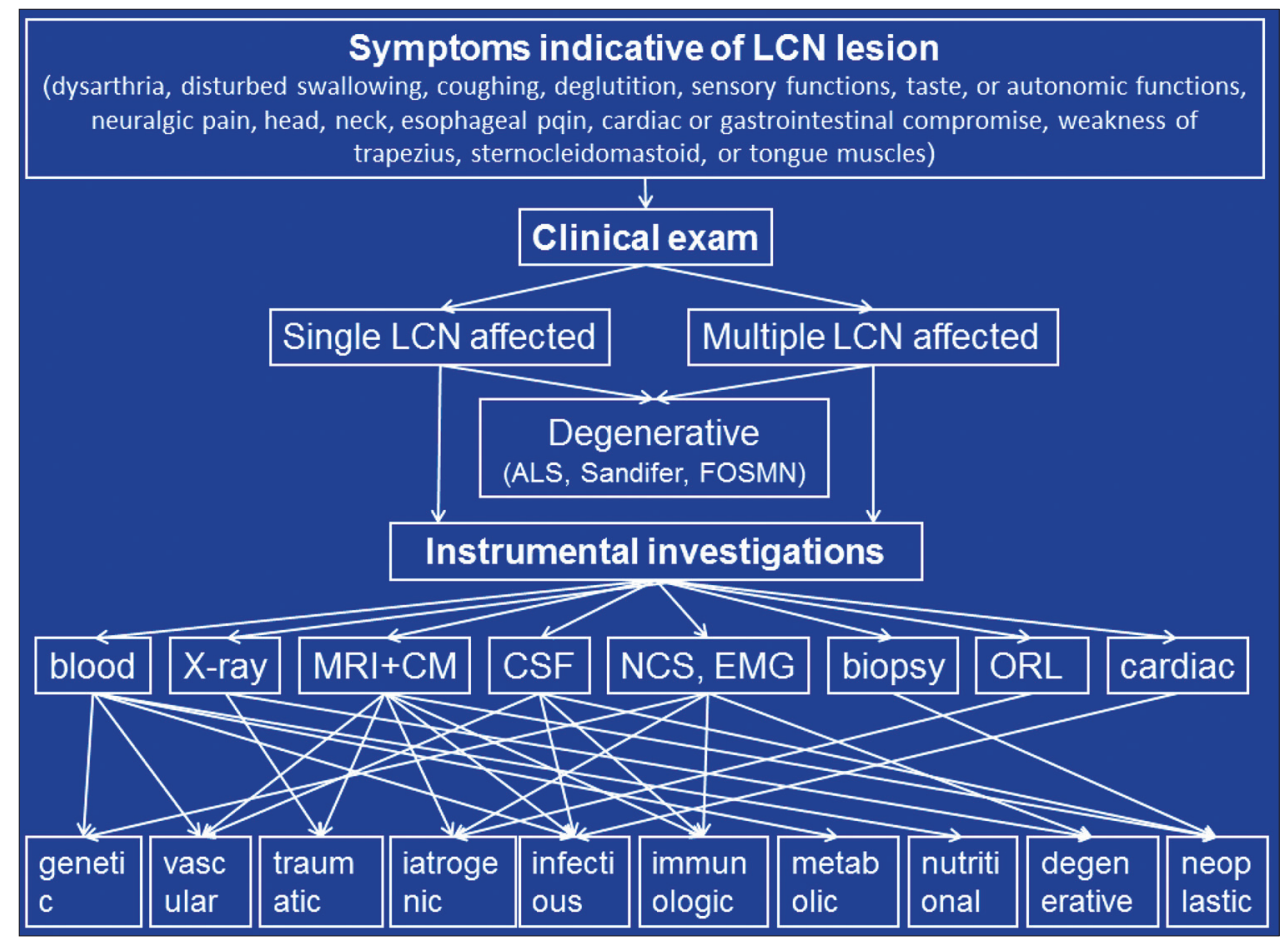

Figure 1: Work-up in case of symptoms indicating lower cranial nerves lesion 
Table 2: Lower cranial nerve lesions

\begin{tabular}{|c|c|c|c|}
\hline Category of disease & Disorders affecting lower cranial nerves & SLCNA & Cranial nerves involved \\
\hline \multirow[t]{4}{*}{ Genetic } & Familial ALS & No & Multiple \\
\hline & BSMA & No & Multiple \\
\hline & Brown-Vialetto-Van Laere syndrome & No & Multiple \\
\hline & Triple-A-syndrome & No & Multiple \\
\hline \multirow[t]{4}{*}{ Vascular } & Stroke & Rarely & Multiple \\
\hline & Aneurysm & No & Multiple (IX, X, XI, XII) \\
\hline & Dissection & No & Multiple \\
\hline & Vasculitis & No & Multiple \\
\hline \multirow[t]{4}{*}{ Traumatic } & Skull base fracture & Yes & Multiple \\
\hline & Atlas fracture & No & Multiple \\
\hline & Fracture of the styloid process & Yes & IX \\
\hline & Traumatic brain injury & No & Multiple \\
\hline \multirow[t]{3}{*}{ latrogenic } & Surgical recanalization of carotid artery & Yes & IX, X, XII \\
\hline & Laryngeal mask & Yes & IX \\
\hline & Thyroid surgery (recurrens nerve) & Yes & $\mathrm{x}$ \\
\hline \multirow[t]{7}{*}{ Infectious } & Diphteria & No & Multiple \\
\hline & Poliomyelitis & No & Multiple \\
\hline & Tetanus & No & Multiple \\
\hline & Sarcoidosis & No & Multiple \\
\hline & Borreliosis & No & Multiple \\
\hline & Ramsey Hunt syndrome & No & Multiple \\
\hline & Tuberculous meningitis & Yes & Multiple \\
\hline \multirow[t]{3}{*}{ Immunologic } & Glossopharyngeal neuralgia (multiple sclerosis) & Yes & IX \\
\hline & Pharyngo-cervical-brachial variant of GBS & No & Multiple \\
\hline & Multiple cranial nerve neuropathy (GBS) & No & Multiple \\
\hline Metabolic & Diabetes & Yes & $\mathrm{x}$ \\
\hline Nutritional & Vitamin B12-deficiency & Yes & $x$ \\
\hline \multirow[t]{4}{*}{ Degenerative } & Eagle-syndrome (elongated styloid process) & Yes & IX \\
\hline & Sporadic ALS & No & Multiple \\
\hline & FOSMN & No & Multiple \\
\hline & Sandifer's syndrome & No & Multiple \\
\hline Neoplastic & Intra and extracranial neoplasms & Yes & Multiple \\
\hline
\end{tabular}

SLCNA: Single lower cranial nerve affected, FOSMN: Facial-onset sensory and motor neuronopathy, ALS: Amyotrophic lateral sclerosis, BSMA: Bulbo-spinal muscular atrophy, GBS: Guillain-Barre-syndrome

\section{Bulbospinal muscular atrophy}

Bulbospinal muscular atrophy (Kennedy disease) is a rare X-linked MND with onset in adolescence or early adulthood. BSMA is caused by a CAG-triplet repeat expansion in the androgen-receptor gene. ${ }^{[30]}$ Clinically, BSMA is characterized by slowly progressive weakness and wasting of all muscles with a predominance of the limb muscles, impairment of speech and swallowing, and muscle cramps. In addition to motor neuropathy, there is also sensory neuropathy, and postural and intention tremor. Nonneurological manifestations include gynecomastia, loss of masculinisation, and erectile dysfunction. Motor manifestations may be asymmetric. Lifespan is usually normal. Leuprorelin and symptomatic therapy is available. ${ }^{[30]}$

\section{Brown-Vialetto-Van Lare-syndrome}

Brown-Vialetto-Van Lare-syndrome is a rare, hereditary disorder characterized by bulbar palsy, respiratory compromise, and sensorineural hearing loss. ${ }^{[31]}$ Brown-Vialetto-Van Lare-syndrome is due to mutations in the SLC52A1 gene encoding the human riboflavin transporter-1. ${ }^{[31]}$ Substitution of riboflavin has a beneficial effect and prolongs life expectancy. ${ }^{[31]}$

\section{Triple-A-syndrome}

Triple-A-syndrome is a rare condition mimicking MND. It follows an autosomal recessive trait of inheritance and is due to mutations in the ALADIN gene, which encodes a nuclear pore complex component. ${ }^{[32]}$ Clinically, triple-A-syndrome is characterized by esophageal achalasia, alacrimia, adrenal insufficiency, and progressive bulbar spinal muscular atrophy with the involvement of upper and lower motor neurons. ${ }^{[32]}$

\section{Hereditary neuropathies}

Rarely, mononeuropathy of the accessory nerve may be a manifestation of hereditary neuropathy with liability to pressure palsies (HNPP). ${ }^{[33]}$ Another LCN involved 
Table 3: Differentials of LCN lesions (disorders which indirectly affect LCN or are associated with LCN lesions)

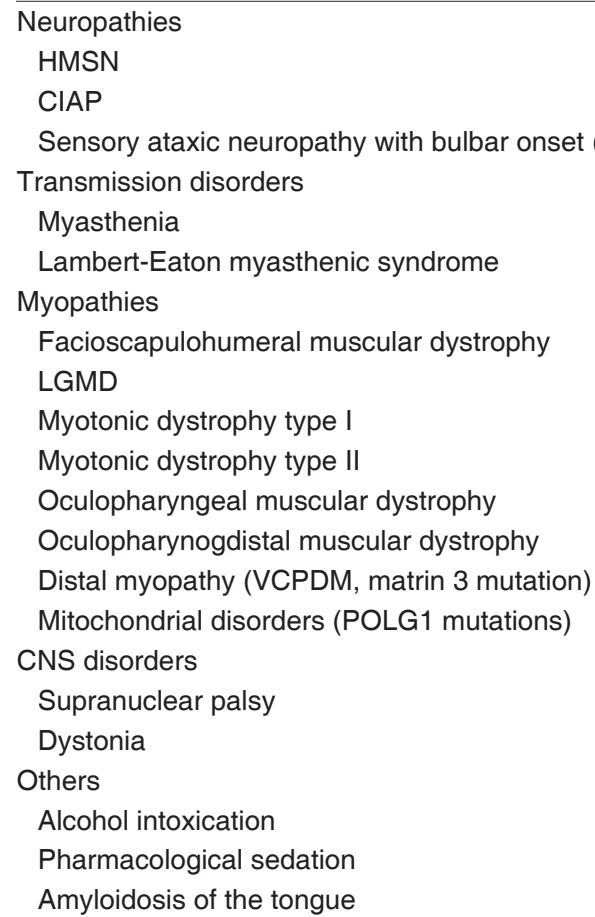

in HNPP is the hypoglossal nerve. ${ }^{[34]}$ The affection of the hypoglossal nerve has been also reported in other types of hereditary neuropathy. ${ }^{[35]}$ Dysarthria may be a feature of hereditary motor and sensory neuropathy Lom. ${ }^{[36]}$ In X-linked Charcot-Marie-Tooth disease due to mutations in the GJB1 gene, neuropathy may be associated with vocal cord paralysis. ${ }^{[37]}$ Vocal cord paralysis has been also reported in congenital hypomyelination. ${ }^{[38]}$

\section{Vascular \\ Stroke}

Ischemic stroke is a frequent cause of LCN affection, particularly if nuclei or fascicles of any of the four LCN are affected (nuclear or fascicular cranial nerve lesions). Additionally, LCN may be secondarily affected in case of supranuclear vascular lesions [Table 3]. According to the location of the ischemic lesion in the brain stem, a dorsal, lateral, paramedian, or median location of the vascular lesion is delineated. In addition, short, long, or circumferential arteries may be involved. Various syndromes are differentiated of which the Wallenberg-syndrome (lateral medullary syndrome) is the most common [Table 1]. More rare ischemic medullary stroke syndromes include the Avellis-syndrome, the Jackson-syndrome, and the Opalski-syndrome [Table 1].

\section{Aneurysm}

Internal carotid artery aneurysm directly underneath the base of the skull may affect the $9^{\text {th }}, 10^{\text {th }}, 11^{\text {th }}$, or $12^{\text {th }}$ cranial nerves. ${ }^{[39]}$ These nerve lesions may result in impaired swallowing or dysarthria but also tongue weakness. ${ }^{[39]}$ Treatment of such aneurysms by parent vessel occlusion may result in shrinkage of the aneurysm and consecutive improvement of the neurological deficits. ${ }^{[39]}$ Additionally, aneurysms of the intracranial vertebral artery may be associated with LCN neuropathy. ${ }^{[40]}$ Aneurysms of the posterior inferior cerebellar artery (PICA) may affect the glossopharyngeal, the vagal, or the accessory nerve. ${ }^{[41]}$

\section{Artery dissection}

Quite frequently internal carotid artery dissection can lead to compression of the hypoglossal nerve. ${ }^{[11,42]}$ Also, dissection of the vertebral artery may go along with hypoglossal palsy. ${ }^{[43]}$ Dissection of the internal carotid artery may even lead to Villaret's-syndrome ${ }^{[44]}$ or Collet-Sicard-syndrome. Vertebral artery dissection may cause Tapia-syndrome [Table 1]. ${ }^{[45]}$ Dissection of the internal carotid artery may result in dysphonia and homolateral shoulder paralysis due to palsy of the vagal and accessory nerves. ${ }^{[4]}$ Horner-syndrome may be another manifestation of a carotid artery dissection, which usually is painful.

\section{Vasculitis}

Rarely, Takayasu vasculitis may lead to injury of the LCN, particularly the glossopharyngeal or the hypoglossal nerves. ${ }^{[4]}$ There is one report about a patient who developed glossopharyngeal neuralgia following an arteritis temporalis. ${ }^{[48]}$ Another patient developed Vernet-syndrome [Table 1] from giant cell arteritis. ${ }^{[49]}$ Collet-Sicard-syndrome [Table 1] has been reported in a single patient with panarteriitis nodosa. ${ }^{[50]}$

\section{Ischemia of lower cranial nerves}

Since $\mathrm{LCN}$ receive their arterial supply from a network of tributaries originating from the internal carotid, external carotid and the vertebro-basilar arteries, it is conceivable that impaired blood supply via these networks results in ischemia of the supplied nerves. ${ }^{[51]}$ Small vessel disease, as well as macroangiopathy, may affect the vasa nervorum of LCN and may thus lead to ischemia causing LCN dysfunction. ${ }^{[51]}$ The vascular supply of LCN is also of relevance for the base of the skull surgery ${ }^{[51]}$ and an issue in interventions by artery embolization in tumor therapy.

\section{Rare vascular causes}

A rare vascular cause of LCN compromise is brainstem cavernoma. ${ }^{[52]}$ Lesion of the LCN may persist despite surgery ${ }^{[53]} \mathrm{A}$ further rarity of a vascular cause is transient 
dysarthria due to compression of the hypoglossal nerve by a calcified persistent hypoglossal artery. ${ }^{[54]}$

\section{Trauma}

\section{Base of the skull fracture}

The base of the skull fractures frequently affect the LCN, particularly if the occipital condyles are involved. ${ }^{[55]}$ The outcome of the base of the skull fractures is poor particularly if LCN are affected. ${ }^{[56]}$ Isolated palsies of the LCN may occur in case of occipital condyle fractures. ${ }^{[57,58]}$ Ipsilateral ${ }^{[59]}$ or contralateral ${ }^{[60]}$ hypoglossal nerve palsy is the most frequent isolated LCN injury from condyle fractures. Early full recovery of these lesions has been reported, ${ }^{[57]}$ but in other cases, palsy persisted for months. Traumatic LCN lesions may not only manifest immediately after the trauma, but with a delay of several days. ${ }^{[61]}$ Prognosis of traumatic LCN lesions is poor if the carotid artery is additionally damaged. ${ }^{[62]}$

\section{Atlas fractures}

Atlas burst fractures rarely cause neurological deficits because of an enlarged opening of the spinal canal at this level and a tendency of the lateral masses to move centrifugally away from the cord posttraumatically. ${ }^{[63]}$ In case of atlas fracture and congenital basilar invagination, however, LCN may be also damaged. ${ }^{[63]}$ Though cranial nerve lesions from atlas fractures are rare, they occasionally occur and affect the $9^{\text {th }}$ through $12^{\text {th }}$ cranial nerve. ${ }^{[64]}$ The most frequent clinical manifestation of cranial nerve involvement is dysphagia, which resolves upon Halo-fixation. ${ }^{[6]}$

\section{Traumatic brain injury}

Traumatic brain injury (TBI) is a leading cause of death or disability, particularly in the younger population. ${ }^{[66]} \mathrm{LCN}$ lesions may be a complication of TBI. ${ }^{[67]}$ Decompression of injured cranial nerves improves the outcome of TBIs. ${ }^{[67]}$ Injury of the vagal nerve may increase vagal tone, which consecutively may diminish the anti-inflammatory capacity of patients with TBI. In the acute phase of TBI patients are thus more vulnerable to infectious disease due to decreased immune response. ${ }^{[66]}$

\section{Fracture of the styloid process}

Fracture of the styloid process may lead to compromise of the $9^{\text {th }}$ cranial nerve. ${ }^{[68]}$ The glossopharyngeal nerve is compromised because it crosses the gap between the process and the first cervical vertebrum. ${ }^{[68]}$ Clinical manifestations of a styloid fracture include neck pain or painful dysphagia. ${ }^{[68]}$ Not only bone fractures, but also traumatic soft tissue lesions may cause LCN dysfunction.

\author{
latrogenic \\ Carotid surgery \\ Carotid surgery may go along with the iatrogenic
}

injury of a single or multiple LCN. ${ }^{[69]}$ Local pressure may lead to impairment of various functions of the $9^{\text {th }}$ or $12^{\text {th }}$ cranial nerves. Particularly during the open restoration of the internal carotid artery, LCN may be iatrogenically injured. ${ }^{[69]}$ In a retrospective study of 543 patients undergoing carotid surgery the glossopharyngeal nerve was damaged in 2 cases $(0.4 \%)$, the vagal nerve in 9 cases $(1.8 \%)$, and the hypoglossal nerve in 7 cases $(1.4 \%) .{ }^{[69]}$ Most of these lesions recovered spontaneously and completely. ${ }^{[69]}$ In a retrospective study of 752 patients undergoing reconstructive surgery of the supra-aortic arteries damage of the glossopharyngeal nerve occurred in 16 cases with complete recovery during a period of 1-6 months. ${ }^{[70]}$

\section{Neck dissection}

Neck dissection refers to a surgical procedure in which the fibro-fatty contents of the neck including cervical lymph nodes are removed for the treatment of cervical lymphatic metastases. It is also applied to malignancies of the skin (head, neck), the thyroid, or the salivary glands. Complications of the procedure affecting LCN include damage of the hypoglossal or accessory nerve. To avoid damage of the accessory nerve from neck dissection, monitoring of accessory function during surgery is increasingly performed. ${ }^{[71]}$

\section{Rare iatrogenic causes}

Rare iatrogenic causes of LCN lesions include unilateral taste disturbance due to local pressure of a classical laryngeal mask onto the nerve, ${ }^{[72]}$ glossopharyngeal or hypoglossal nerve palsy after tonsillectomy, or vagal nerve palsy after obesity treatment. ${ }^{[73]}$ During bariatric surgery the vagal may be accidentally compromised without severe consequences. ${ }^{[74]}$ Thyroid surgery may be complicated by injury of the accessory and recurrent nerve. ${ }^{[75]}$ Rhinoplasty may be complicated by Tapia-syndrome. ${ }^{[76]}$

\section{Infectious \\ Varicella-zoster virus}

Varicella-zoster virus infection involving the LCN may manifest as Ramsey-Hunt-syndrome, Garcin-syndrome, or Jugular-foramen-syndrome. Ramsey-Hunt-syndrome is caused by infection with the virus of the geniculate ganglion of the facial nerve. ${ }^{[77]}$ Clinically, it is characterized by $7^{\text {th }}$ cranial nerve palsy, otic pain, and herpetic vesicles around the auricle and external auditory canal. ${ }^{[77,78]}$ Occasionally, LCN may be additionally involved, particularly the vagal nerve which may manifest with transient dysphagia. ${ }^{[77,78]}$ Jugular-foramen-syndrome is characterized by acute onset dysphagia, dysphonia, and accompanied or preceded by cranial, cervical, or pharyngeal pain. ${ }^{[13]}$ The most frequent cause of 
Jugular-foramen-syndrome is herpes zoster oticus with herpetic eruptions of the skin or the mucosa. MRI may reveal contrast enhancement around the jugular foramen, suggesting inflammation of the glossopharyngeal or vagal nerve ganglia. ${ }^{[13]}$ The diagnosis is confirmed by demonstration of VZV-DNA or VZV-antibodies in the CSF [Figure 1]. ${ }^{[13]}$ If there is unilateral herpes zoster infection of the larynx, ipsilateral LCN may be affected. ${ }^{[79]}$ In rare cases VZV-infection may present as Garcin-syndrome. ${ }^{[80]}$

\section{Diphtheria}

Diphtheria is characterized by initial infection of the upper airway tract with Corynebacterium diphteriae, which later is secondarily complicated by systemic radiculoneuropathy also affecting the $9^{\text {th }}$ or $10^{\text {th }}$ cranial nerve. Clinically, these patients present with paralyzed accommodation, palatal paralysis, tongue weakness, and sensory $>$ motor polyneuropathy diphtheria is frequently associated with cardiomyopathy and arrhythmias. Paralysis of the diaphragm occurs in $1 / 3$ of the cases. In severe cases laryngospasm may develop. Autonomic involvement includes sinustachycardia, bladder dysfunction, or arterial hypotension. Occasionally, there may be facial weakness, ophthalmoparesis, or optic atrophy.

\section{Poliomyelitis}

Poliomyelitis is caused by an RNA-enterovirus and occurs in only $5-10 \%$ of the infected patients. It starts with fever, myalgia, and nonspecific gastrointestinal symptoms. 4-20 days after the infection patients develop meningitis with headache and stiff neck followed by weakness of limb muscles. ${ }^{[81]}$ In $20 \%$ of the cases, poliomyelitis is associated with bulbar involvement. ${ }^{[81]}$ Cranial nerves are variably affected. If the $7^{\text {th }}$ cranial nerve is affected, hemifacial atrophy may ensue. ${ }^{[82]}$ In other cases, the $5^{\text {th }}, 9^{\text {th }}, 10^{\text {th }}$, and $11^{\text {th }}$ cranial nerves may be involved. ${ }^{[83]}$ Skeletal muscles supplied by these nerves become atrophic. ${ }^{[83]}$

\section{Tetanus}

Tetanus is an infection caused by the endotoxins of Clostridium tetani, which block the presynaptic SNARE protein. It may occur focally or generalized. Entry of the toxin into the body is in $75 \%$ of the cases an acute wound. Despite modern medicine, mortality still ranges between $15 \%$ and $30 \%$. Among the cranial nerves, the facial nerve is most commonly affected. Others are the nerves supplying the extra-ocular muscles, or the hypoglossal nerve. Rarely, the $9^{\text {th }}$ or $10^{\text {th }}$ cranial nerve is affected. ${ }^{[81]}$

\section{Botulinism}

Concerning the entrance of the bacterium into the body, foodborne botulism and wound botulism are differentiated. Concerning age at onset, infant botulism (in one fifth of the cases via ingestion of honey) and adult intestinal toxaemia are differentiated. Accidentally, botulism may be caused by overdosing therapeutic botulinum toxin. In rare cases Clostridium botulinum infection may involve cranial nerves. ${ }^{[84]}$ Particularly hemorrhaghe within the vagal nerve has been reported. ${ }^{[84]}$

\section{Borreliosis}

Borreliosis and Lyme disease are due to an infection with the spirochete Borrelia burgdorferi. In the majority of the cases it is transmitted from ticks to humans. Occasionally, the central nervous system (CNS) is affected manifesting as headache, sleep disturbance, papilledema, meningitis, meningo-radiculitis, myelitis, affection of the cranial nerves, ataxia, chorea, and altered mental state. LCN are rarely involved. ${ }^{[85]}$ Manifestations attributable to LCN involvement resolved upon adequate antibiotic treatment in a single patient. ${ }^{[85]}$

\section{Tuberculous meningitis}

Affection of the LCN by tuberculous meningitis is rare and usually has a poor outcome. ${ }^{[86]}$ Involvement of the LCN in tuberculous meningitis may manifest clinically as speech disturbance (slurring) ${ }^{[86]}$ If tuberculous spondylitis involves the craniocervical junction, affected patients may present with isolated hypoglossal nerve palsy. ${ }^{[8]}$

\section{Immunological \\ Sarcoidosis}

Sarcoidosis is an inflammatory, granulomatous, systemic disease. In about $25 \%$ of the cases involvement of the nervous system occurs (neurosarcoidosis). ${ }^{[88]}$ Involvement of the cranial nerves is the most common abnormality in neurosarcoidosis and most frequently affects the $7^{\text {th }}$ and second most frequently the $2^{\text {nd }}$ cranial nerve. Only rarely, the $8^{\text {th }}, 9^{\text {th }}$, or $10^{\text {th }}$ cranial nerves are being affected. In a retrospective study of 54 patients with neurosarcoidosis, those with LCN involvement had a slightly better outcome than those with optic nerve involvement. ${ }^{[88]}$ Clinical manifestations of neurosarcoidosis usually resolve upon administration of steroids. ${ }^{[89]}$

\section{Multiple cranial nerve neuropathy}

Multiple cranial nerve neuropathy is the pharyngo-facial variant of Guillain-Barre-syndrome (GBS) ${ }^{[90]}$ Affected patients present with facial swelling, bilateral facial palsy, and bulbar palsy with dysphagia or aspiration. ${ }^{\left[{ }^{[0]}\right.}$ There may also be weakness of the neck, the upper limbs, the hips, or the facial muscles. In $70 \%$ of the cases, an upper respiratory tract infection and in 30\% diarrhea or other gastrointestinal problems precede the immune neuropathy. Infectious 
agents are the campylobacter jejunii or the cytomegaly virus. Intravenous immunoglobulins have a beneficial effect. In a case of Miller-Fisher-syndrome associated with Bickerstaff encephalitis, the patient presented with ophthalmoplegia, bilateral facial palsy, dysphagia, dysarthria, neck weakness, distal quadriparesis, and ataxia. ${ }^{[91]}$ These abnormalities improved gradually upon intravenous immunoglobulins. ${ }^{[91]}$

\section{Pharyngo-cervical-brachial variant of Guillain-Barre-syndrome}

This GBS variant manifests with dysphagia, weakness of facial muscles, neck flexors, and proximal upper limb muscles, ophthalmoplegia, ataxia, and autonomic dysfunction (heart rate, bladder). Laboratory and electrophysiological investigations are similar to those in GBS.

Chronic inflammatory demyelinating polyneuropathy Rarely, LCN are involved in chronic inflammatory demyelinating polyneuropathy (CIDP) manifesting as hypogeusia due to the involvement of the glossopharyngeal nerve. ${ }^{[92]}$ Much more frequently than the glossopharyngeal nerve, the hypoglossal nerve may be affected in CIDP patients. ${ }^{[93]}$

\section{Multiple sclerosis}

Neuropathic pain, manifesting as cranial neuralgia, is a frequent feature of multiple sclerosis. ${ }^{[94]}$ The most well-known LCN neuralgia is the one of the glossopharyngeal nerve. Demyelination in the centrally myelinated part of the cranial nerve roots is held responsible for the development of pain. ${ }^{[94]}$ The most frequent neuralgia of the LCN in multiple sclerosis is glossopharyngeal neuralgia. ${ }^{[15]}$

\section{Metabolic \\ Diabetes}

Autonomic neuropathy from diabetes may also affect the vagal nerve and its branches and may be associated with cardiovascular and gastrointestinal compromise. ${ }^{[95]}$ In humans or animals with severe hyperglycemia, impairment of the cardiac autonomic nervous system may occur. ${ }^{[96,97]}$ Diabetic gastroparesis is well-known but poorly understood phenomenon, which may also be due to affection of the autonomic innervation by the vagal nerve. ${ }^{[98]}$

\section{Nutritional}

Vitamin $B_{12}$ deficiency

Rarely, Vitamin- $B_{12}$ deficiency may be the cause of unilateral vocal cord palsy. ${ }^{[99]}$ Among cranial nerves, the optic nerve is the one most frequently affected in $\mathrm{B}_{12}$-deficiency. ${ }^{[99]}$ Folate deficiency has not been reported as a cause of LCN lesions. Autonomic dysfunction with vagal withdrawal and defective sympathetic activation has been reported in patients with cobalamin deficiency. ${ }^{[100]}$

\section{Degenerative}

\section{Amyotrophic lateral sclerosis}

Usually, ALS manifests clinically in adulthood as a continuum between the exclusive affection of the upper motor neurons and exclusive affection of lower motor neurons. ${ }^{[29]}$ The affection of the LCN leads to a bulbar syndrome including slurred and dysarthria and dysphagia. LCN may be affected already at the onset of the disease (bulbar-onset ALS), or following the affection of the limb muscles (limb-onset ALS). In ALS with bulbar involvement, a dynamic collapse of the airway due to the gravitational pull of the mandible (mandibula ptosis) may occur in the supine position.

\section{Facial onset sensory and motor neuronopathy}

Facial onset sensory and motor neuronopathy is a rare, slowly progressive neurodegenerative disorder clinically characterized by numbness and paresthesias initially in a trigeminal nerve distribution followed by spreading to the scalp, neck, upper trunk, and upper limbs. ${ }^{[101]}$ Later in the course, patients develop muscle cramps, fasciculations, muscle weakness and wasting, dysphagia, and dysarthria. ${ }^{[101]}$ Nerve conduction studies reveal a caudally descending sensorimotor neuropathy. ${ }^{[101]}$ An autopsy may show loss of motoneurons in the hypoglossal nucleus and cervical anterior horns.

\section{Sandifer's syndrome}

Sandifer's syndrome is a gastrointestinal disorder characterized by reflex torticollis following deglutition in patients with gastro-esophageal reflux or hiatal hernia. ${ }^{[102]}$ Sandifer's syndrome is regarded as a vagal reflex triggered by afferent impulses transmitted via general visceral afferents to the nucleus tractus solitarii and from there to the nucleus ambiguus and the nucleus dorsalis nervi vagi. From the latter, visceral efferents reach the accessory nerve via hypothetical anastomoses to innervate the trapezius and sternocleidomastoid muscles. ${ }^{[102]}$

\section{Eagle-syndrome}

Eagle-syndrome, also known as syndrome of the elongated styloid process, is characterized by cervical pain, which can be enhanced by head rotation, chewing, or head extension. ${ }^{[103]}$ Neck or throat pain usually radiates to the ipsilateral ear. Other symptoms include foreign body sensation, dysphagia, or facial pain. ${ }^{[104]}$ Symptoms are due to an elongated styloid process or an ossified stylohyoid ligament. The ossification of the ligament leads to throat symptoms due to the affection of the glossopharyngeal nerve. ${ }^{[103]}$ 


\section{Chiari malformation}

In rare cases, Chiari-I malformation may be associated with the affection of the hypoglossal nerve.${ }^{[105]}$ More frequently, Chiari-I malformation causes glossopharyngeal neuralgia. ${ }^{[106]}$ Chiari-I malformation may also compromise the vagal nerve. Chiari-I malformation may lead to compression of the LCN between the PICA and the herniated cerebellar tonsil. ${ }^{[107]}$

\section{Neoplasms}

A number of benign or malignant intra- or extra-cranial neoplasms are associated with lesions of the LCN (base of the skull syndromes). Also, bone metastases of the skull base may damage LCN. ${ }^{[108]}$ Intra-cranial neoplasms may be further divided into those located intra-cerebrally and those located extra-cerebrally. Among the extracranial neoplasms, those located just below the skull and those of the neck are differentiated. Intrinsic brain tumors may affect the nuclei or intra-parenchymatous nerve tracts. Malignant spread within the CSF space affects cranial nerves and nerve roots. Tumors affecting the cranial nerves outside the bony skull may spread in an antero-or retrograde fashion.

Intra-cerebral neoplasms affecting nuclei of LCN include the posterior fossa ependymoma, ${ }^{[109]}$ choroid plexus papilloma, ${ }^{[110]}$ primary CNS lymphoma, ${ }^{[111]}$ or rarely metastasis. ${ }^{[112]}$ Extra-axial neoplasms affecting the LCN include cisternal meningeomas, ${ }^{[113]}$ extra-axial cavernomas, ${ }^{[114]}$ choroid plexus papillomas, ${ }^{[115]}$ intracranial Schwannomas, ${ }^{[116]}$ or metastasis. ${ }^{[117]}$ Leptomeningeal carcinomatosis involving the LCN is less frequent than involvement of upper cranial nerves. ${ }^{[118]}$ Suspected leptomeningeal carcinomatosis may not always be confirmed at autopsy. Usually, however, an autopsy in meningeal carcinomatosis may show squamous-type carcinoma cells scattered in the cerebro-spinal leptomeninges and perineurium of almost all spinal and cranial nerve roots, causing severe axonal degeneration. ${ }^{[119]}$ Involvement of the leptomeninges in lymphomatoid granulomatosis may also damage LCN. ${ }^{[120]}$ Bone metastases of the base of the skull, which are usually painful, are a frequent cause of LCN dysfunction including Collet-Sicard-syndrome. ${ }^{[108,121]}$

The most frequent neoplasms of the jugular foramen are the paragangliomas, ${ }^{[113]}$ followed by Schwannomas, ${ }^{[122]}$ neuroendocrine carcinoma, ${ }^{[123]}$ and meningeomas. ${ }^{[124]}$ Paraganglioma accounts for $<1 \%$ of neoplasms in the head-neck region. Traditionally, paragangliomas are considered as benign, slowly growing, locally invasive, encapsulated and highly vascularised tumors. ${ }^{[22]}$ Paragangliomas of the neck may even cause Collet-Sicard-syndrome. ${ }^{[22]}$ Neoplasms originating from one of the LCN include the hypoglossal Schwannoma, ${ }^{[125]}$ the vagal nerve Schwannoma, ${ }^{[126]}$ and the neurilemmoma of the vagal nerve. ${ }^{[127]}$ The base of the skull neoplasms affecting LCN include the hemangiopericytoma, ${ }^{[128]}$ the glomus tumor, ${ }^{[129]}$ chordomas, ${ }^{[130]}$ osteosarcoma, or metastasis. Neoplasms of the neck may also injure LCN. Recurrent squamous carcinoma metastatic to the neck may directly infiltrate the glossopharyngeal or vagal nerves. ${ }^{[131]}$ Neck fibrosarcoma as well as multiple myeloma, hypoglossal Schwannoma, jugular foramen neurinoma, jugular foramen metastatic melanoma, or hemangiopericytoma may cause Collet-Sicard-syndrome. Tonsillar carcinoma invading the parapharyngeal space may lead to hypersensitivity of the carotid sinus coupled with glossopharyngeal neuralgia. ${ }^{[132]}$ LCN lesions may also originate from perineural spread of a facial squamous

\section{Table 4: Disorders specifically affecting a LCN and disorders with LCN involvement but diagnosed upon systemic manifestations}

\begin{tabular}{|c|c|}
\hline Disorder & Affected LCN nerve \\
\hline \multicolumn{2}{|l|}{ Disorders specifically affecting LCN } \\
\hline Hereditary neuropathies & $12^{\text {th }}$ \\
\hline PICA-aneurysm & $9^{\text {th }}, 10^{\text {th }}, 11^{\text {th }}$ \\
\hline Artery dissection & $10^{\text {th }}, 11^{\text {th }}$ \\
\hline Ischemia of $\mathrm{CN}$ & $9^{\text {th }}$ through $12^{\text {th }}$ \\
\hline Calcified persisting hypoglossal artery & $12^{\text {th }}$ \\
\hline Condyle fracture & $12^{\text {th }}$ \\
\hline Atlas fracture & $9^{\text {th }}$ through $12^{\text {th }}$ \\
\hline Styloid fracture & $9^{\text {th }}$ \\
\hline Carotid surgery & $9^{\text {th }}, 10^{\text {th }}, 12^{\text {th }}$ \\
\hline Neck dissection & $11^{\text {th }}, 12^{\text {th }}$ \\
\hline Poliomyelitis & $9^{\text {th }}$ through $11^{\text {th }}$ \\
\hline Tetanus & $9^{\text {th }}, 10^{\text {th }}, 12^{\text {th }}$ \\
\hline Botulinism & $10^{\text {th }}$ \\
\hline Tuberculous meningitis & $12^{\text {th }}$ \\
\hline Neuralgia & $9^{\text {th }}$ \\
\hline Eagle-syndrome & $9^{\text {th }}$ \\
\hline Chiari malformation & $9^{\text {th }}, 10^{\text {th }}$ \\
\hline Schwannoma & $10^{\text {th }}, 12^{\text {th }}$ \\
\hline Tonsillar carcinoma & $9^{\text {th }}$ \\
\hline Metastasis & $9^{\text {th }}, 10^{\text {th }}$ \\
\hline \multicolumn{2}{|l|}{$\begin{array}{l}\text { Disorders with LCN involvement } \\
\text { diagnosed upon systemic manifestations }\end{array}$} \\
\hline ALS & All \\
\hline Borreliosis & All \\
\hline GBS & All \\
\hline CIDP & $9^{\text {th }}, 12^{\text {th }}$ \\
\hline Multiple sclerosis & All \\
\hline Sarcoidosis & All \\
\hline Diabetes & All \\
\hline Vitamin deficiency & All \\
\hline FOSMN-syndrome & $12^{\text {th }}$ \\
\hline Sandifer's syndrome & $11^{\text {th }}$ \\
\hline
\end{tabular}


cell carcinoma. ${ }^{[133]}$ In a report of 3 cases, super-selective arterial embolization of paragangliomas with ethylene vinyl alcohol resulted in damage of the $10^{\text {th }}, 11^{\text {th }}$, or $12^{\text {th }}$ cranial nerve with recovery in only one patient. ${ }^{[134]}$

\section{Conclusions}

This review about disorders of the LCN shows that causes of LCN lesions are heterogeneous. Causes of LCN lesions may be classified as genetic, vascular, traumatic, iatrogenic, infectious, immunologic, nutritional, metabolic, degenerative, or neoplastic. LCN may be affected as a single nerve or as multiple LCN. LCN may be affected together with more proximal cranial nerves, together with CNS disease, or together with nonneurological disorders. There are disorders which specifically affect LCN and multisystem disorders with nondominant LCN involvement [Table 4]. If LCN lesions are suspected upon typical symptoms and signs, specific instrumental investigations may confirm the suspected LCN lesion [Figure 1]. Affection of multiple LCN is much more frequent than the affection of a single LCN. Treatment of LCN lesions depends on the underlying cause. An effective treatment is available in the majority of the cases but the requirement for complete recovery is the prompt and correct diagnosis. To correctly assess complaints resulting from LCN lesions, precise knowledge about the anatomy and physiology of the area is a prerequisite.

\section{References}

1. Netter FH. Atlas of Human Anatomy. $6^{\text {th }}$ ed. Elsevier, 2014.

2. Trepel M. Neuroanatomy. Structure and Function. $3^{\text {rd }}$ new and revised edition. Urban and Fischer, Munich a. o., 2004.

3. Ozveren MF, Türe U, Ozek MM, Pamir MN. Anatomic landmarks of the glossopharyngeal nerve: A microsurgical anatomic study. Neurosurgery 2003;52:1400-10.

4. Dinh QT, Heck S, Le DD, Bals R, Welte T. Pathophysiology, diagnostics and therapy of chronic cough: Neuronal reflexes and antitussiva. Pneumologie 2013;67:327-34.

5. Samandari F, Resßig D. Functional anatomy of cranial nerves and the vegetative nervous system. For medical doctors and dentists. $2^{\text {nd }}$ Edition, DeGryter, Berlin, New York; 1994.

6. Haines DE. Neuroanatomy: An Atlas of Structures, Sections, and Systems. Hagerstown, MD: Lippincott Williams and Wilkins; 2004.

7. Benninger $\mathrm{B}, \mathrm{McNeil} J$. Transitional nerve: A new and original classification of a peripheral nerve supported by the nature of the accessory nerve (CN XI). Neurol Res Int 2010;2010:476018.

8. Oh CS, Chung IH, Koh KS, Kim HJ, Kim SS. Intradural anastomoses between the accessory nerve and the posterior roots of cervical nerves: Their clinical significance. Clin Anat 2001;14:424-7.

9. Shoja MM, Oyesiku NM, Shokouhi G, Griessenauer CJ, Chern JJ, Rizk EB, et al. A comprehensive review with potential significance during skull base and neck operations, Part II: Glossopharyngeal, vagus, accessory, and hypoglossal nerves and cervical spinal nerves 1-4. Clin Anat 2014;27:131-44.

10. Walker HK. Cranial nerve XII: The hypoglossal nerve. In: Walker HK, Hall WD, Hurst JW, editors. Clinical Methods: The History, Physical, and Laboratory Examinations. $3^{\text {rd }}$ edition. Ch. 65. Boston: Butterworths; 1990. 11. De Santis F, Martini G, Thüringen P, Thaler M, Mani G, Steckholzer K.
Internal carotid artery dissection after inferior alveolar nerve block for third molar dental care presented as hypoglossal nerve palsy. Vasc Endovascular Surg 2012;46:591-5.

12. Tjakkes GH, Rijnvis DJ, Timmenga NM, Stegenga B. A patient with glossopharyngeal neuralgia: A (un) known trap. Ned Tijdschr Tandheelkd 2008;115:263-5.

13. GaitourE, Nick ST, Roberts C, Gonzalez-Toledo E, Munjampalli S, Minagar A, et al. Glossopharyngeal neuralgia secondary to vascular compression in a patient with multiple sclerosis: A case report. J Med Case Rep 2012;6:213.

14. Langner S, Schroeder HW, Hosten N, Kirsch M. Diagnosing neurovascular compression syndromes. Rofo 2012;184:220-8.

15. Carrieri PB, Montella S, Petracca M. Glossopharyngeal neuralgia as onset of multiple sclerosis. Clin J Pain 2009;25:737-9.

16. Kawasaki M, Hatashima S, Matsuda T. Non-surgical therapy for bilateral glossopharyngeal neuralgia caused by Eagle's syndrome, diagnosed by three-dimensional computed tomography: A case report. J Anesth 2012;26:918-21

17. Kodama S, Oribe K, Suzuki M. Superior laryngeal neuralgia associated with deviation of the hyoid bone. Auris Nasus Larynx 2008;35:429-31.

18. Aydin O, Ozturk M, Anik Y. Superior laryngeal neuralgia after acute laryngitis and treatment with a single injection of a local anesthetic. Arch Otolaryngol Head Neck Surg 2007;133:934-5.

19. Bagatzounis A, Geyer G. Lateral pharyngeal diverticulum as a cause of superior laryngeal nerve neuralgia. Laryngorhinootologie 1994;73:219-21.

20. Takahashi Sato K, Suzuki M, Izuha A, Hayashi S, Isosu T, Murakawa M. Two cases of idiopathic superior laryngeal neuralgia treated by superior laryngeal nerve block with a high concentration of lidocaine. J Clin Anesth 2007;19:237-8.

21. Varedi P, Shirani G, Karimi A, Varedi P, Khiabani K, Bohluli B. Tapia syndrome after repairing a fractured zygomatic complex: A case report and review of the literature. J Oral Maxillofac Surg 2013;71:1665-9.

22. Khalid S, Zaheer S, Khalid M, Zaheer S, Raghuwanshi RK. Collet-Sicard syndrome secondary to a large glomus jugulotympanicum. Ann Saudi Med 2013;33:407-10.

23. Jo YR, Chung CW, Lee JS, Park HJ. Vernet syndrome by varicella-zoster virus. Ann Rehabil Med 2013;37:449-52.

24. Aida Y, Igarashi A, Inoue S, Abe S, Shibata Y, Kubota I. A case of lung adenocarcinoma exhibiting Garcin syndrome. Nihon Kokyuki Gakkai Zasshi 2010;48:66-9.

25. Ono N, Sakabe A, Nakajima M. Herpes zoster oticus-associated jugular foramen syndrome. Brain Nerve 2010;62:81-4.

26. Kennelly KD. Electrodiagnostic approach to cranial neuropathies. Neurol Clin 2012;30:661-84.

27. Ravits J, Appel S, Baloh RH, Barohn R, Brooks BR, Elman L, et al. Deciphering amyotrophic lateral sclerosis: What phenotype, neuropathology and genetics are telling us about pathogenesis. Amyotroph Lateral Scler Frontotemporal Degener 2013;14 Suppl 1:5-18.

28. Verma A, Tandan R. RNA quality control and protein aggregates in amyotrophic lateral sclerosis: A review. Muscle Nerve 2013;47:330-8.

29. Finsterer J, Burgunder JM. Recent progress in the genetics of motor neuron disease. Eur J Med Genet 2014;57:103-12.

30. Finsterer J. Perspectives of Kennedy's disease. J Neurol Sci 2010;298:1-10.

31. Bosch AM, Stroek K, Abeling NG, Waterham HR, Ijlst L, Wanders RJ. The Brown-Vialetto-Van Laere and Fazio Londe syndrome revisited: Natural history, genetics, treatment and future perspectives. Orphanet J Rare Dis 2012;7:83.

32. Ikeda M, Hirano M, Shinoda K, Katsumata N, Furutama D, Nakamura K, et al. Triple A syndrome in Japan. Muscle Nerve 2013;48:381-6.

33. Felice KJ, Leicher CR, DiMario FJ Jr. Hereditary neuropathy with liability to pressure palsies in children. Pediatr Neurol 1999;21:818-21.

34. Winter WC, Juel VC. Hypoglossal neuropathy in hereditary neuropathy with liability to pressure palsy. Neurology 2003;61:1154-5.

35. Nakamura N, Oka N, Nakamura S, Akiguchi I, Kashii S. A case with hereditary motor and sensory neuropathy with multiple cranial nerves involvement. Rinsho Shinkeigaku 1995;35:516-20.

36. Dackovic J, Keckarevic-Markovic M, Komazec Z, Rakocevic-Stojanovic V, Lavrnic D, Stevic Z, et al. Hereditary motor and sensory neuropathy Lom type in a Serbian family. Acta Myol 2008;27:59-62.

37. Li QH, Liu KX, Feng JL, Zeng AY, Li H, Wu L, et al. A new mutation in the GJB1 gene of a Chinese family with Charcot-Marie-Tooth disease 
associated with vocal cord paresis. Zhonghua Yi Xue Yi Chuan Xue Za Zhi 2010;27:497-500.

38. Hahn JS, Henry M, Hudgins L, Madan A. Congenital hypomyelination neuropathy in a newborn infant: Unusual cause of diaphragmatic and vocal cord paralyses. Pediatrics 2001;108:E95.

39. Koscielny S, Koch J, Behrendt W. Aneurysm of the internal carotid artery - A differential diagnosis of paralysis of the caudal cranial nerves. HNO 2003;51:728-32.

40. Kassam AB, Mintz AH, Gardner PA, Horowitz MB, Carrau RL, Snyderman $\mathrm{CH}$. The expanded endonasal approach for an endoscopic transnasal clipping and aneurysmorrhaphy of a large vertebral artery aneurysm: Technical case report. Neurosurgery 2006;59:ONSE162-5.

41. Wu J, Xu F, Yu ZQ, Zhou YX, Cui G, Li XD, et al. Clinical experiences of ruptured posteroinferior cerebellar artery aneurysms and anatomical analysis in the cadaver in a single center of China. Clin Neurol Neurosurg 2012;114:366-71.

42. Riancho J, Infante J, Mateo JI, Berciano J, Agea L. Unilateral isolated hypoglossal nerve palsy associated with internal carotid artery dissection. J Neurol Neurosurg Psychiatry 2013;84:706.

43. Mahadevappa K, Chacko T, Nair AK. Isolated unilateral hypoglossal nerve palsy due to vertebral artery dissection. Clin Med Res 2012;10:127-30.

44. Mizutani S, Tsukuura R, Matsumura K, Watanabe M, Hanakawa I, Kamata T. Villaret's syndrome caused by internal carotid artery dissection. Rinsho Shinkeigaku 2011;51:608-11.

45. Al-Sihan M Jr, Schumacher M, Löhle E. Tapia syndrome caused by a vertebral artery dissection. Ear Nose Throat J 2011;90:313-4.

46. Cuno A, Becker M, Leuchter I. Dysphonia as a manifestation of internal carotid artery dissection: A case report. Rev Med Suisse 2010;6:1868-70.

47. Stepien A, Durka-Kesy M, Warczynska A. Compression neuropathy of cranial nerves in the course of Takayasu arteritis. Neurol Neurochir Pol 2007;41:557-61.

48. Maxit M, Vetromile O. Temporal arteritis, glossopharyngeal neuralgia, and syncope. Medicina (B Aires) 1993;53:89-90.

49. Jeret JS. Giant cell arteritis and Vernet's syndrome. Neurology 1999;52:677.

50. Krystkowiak P, Vermersch P, Maurage CA, Petit H. Collet-Sicard syndrome disclosing periarteritis nodosa. Rev Neurol (Paris) 1998;154:777-9.

51. Hendrix P, Griessenauer CJ, Foreman P, Loukas M, Fisher WS $3^{\text {rd }}$, Rizk E, et al. Arterial supply of the lower cranial nerves: A comprehensive review. Clin Anat 2014;27:108-17.

52. Chen L, Zhao Y, Zhou L, Zhu W, Pan Z, Mao Y. Surgical strategies in treating brainstem cavernous malformations. Neurosurgery 2011;68:609-20.

53. Samii M, Eghbal R, Carvalho GA, Matthies C. Surgical management of brainstem cavernomas. J Neurosurg 2001;95:825-32.

54. Meila D, Wetter A, Brassel F, Nacimiento W. Intermittent hypoglossal nerve palsy caused by a calcified persistent hypoglossal artery: An uncommon neurovascular compression syndrome. J Neurol Sci 2012;323:248-9.

55. Legros B, Fournier P, Chiaroni P, Ritz O, Fusciardi J. Basal fracture of the skull and lower (IX, X, XI, XII) cranial nerves palsy: Four case reports including two fractures of the occipital condyle - A literature review. J Trauma 2000;48:342-8.

56. Caroli E, Rocchi G, Orlando ER, Delfini R. Occipital condyle fractures: Report of five cases and literature review. Eur Spine J 2005;14:487-92.

57. Bozkurt G, Hazer B, Yaman ME, Akbay A, Akalan N. Isolated paralysis of glossopharyngeal and vagus nerve associated with type II occipital condyle fracture: Case report. Childs Nerv Syst 2010;26:719-22.

58. Smejkal K, Lochman P, Holecek T. Post-traumatic hypoglossal nerve paresis due to occipital condyle fracture. Acta Chir Orthop Traumatol Cech 2009;76:335-7.

59. Cirak B, Akpinar G, Palaoglu S. Traumatic occipital condyle fractures. Neurosurg Rev 2000;23:161-4.

60. Inci MF, Demir CF, Ozkan F, Yildiz M. Unusual presentation of occipital condyle fracture: Contralateral hypoglossal nerve palsy. Neurol India 2012;60:550-2.

61. Yildirim A, Gurelik M, Gumus C, Kunt T. Fracture of skull base with delayed multiple cranial nerve palsies. Pediatr Emerg Care 2005;21:440-2.

62. Cahill DW, Rao KC, Ducker TB. Delayed carotid-cavernous fistula and multiple cranial neuropathy following basal skull fracture. Surg Neurol 1981;16:17-22.

63. Hsu HP, Chen ST, Chen CJ, Ro LS. A case of Collet-Sicard syndrome associated with traumatic atlas fractures and congenital basilar invagination. J Neurol Neurosurg Psychiatry 2004;75:782-4.

64. Henche HR, Lücking CH, Schumacher M. Atlas fractures with paralysis of the caudal cranial nerves. A case report. Z Orthop Ihre Grenzgeb 1994;132:394-8.

65. Dettling SD, Morscher MA, Masin JS, Adamczyk MJ. Cranial nerve IX and $\mathrm{X}$ impairment after a sports-related Jefferson (C1) fracture in a 16-year-old male: A case report. J Pediatr Orthop 2013;33:e23-7.

66. Kox M, Pompe JC, Pickkers P, Hoedemaekers CW, van Vugt AB, van der Hoeven JG. Increased vagal tone accounts for the observed immune paralysis in patients with traumatic brain injury. Neurology 2008;70:480-5.

67. Jin H, Wang S, Hou L, Pan C, Li B, Wang H, et al. Clinical treatment of traumatic brain injury complicated by cranial nerve injury. Injury 2010;41:918-23.

68. Haidar A, Kalamchi S. Painful dysphagia due to fracture of the styloid process. Oral Surg Oral Med Oral Pathol 1980;49:5-6.

69. Myrcha P, Ciostek P, Szopinski P, Noszczyk W. Damage to cranial and peripheral nerves following patency restoration of the internal carotid artery. Neurol Neurochir Pol 2001;35:415-21.

70. Sandmann W, Hennerici M, Aulich A, Kniemeyer H, Kremer KW. Progress in carotid artery surgery at the base of the skull. J Vasc Surg 1984;1:734-43.

71. Lima LP, Amar A, Lehn CN. Spinal accessory nerve neuropathy following neck dissection. Braz J Otorhinolaryngol 2011;77:259-62.

72. Arimune M. Taste disturbance after general anesthesia with classic laryngeal mask airway (CLM). Masui 2007;56:820-1.

73. Kral JG, Paez W, Wolfe BM. Vagal nerve function in obesity: Therapeutic implications. World J Surg 2009;33:1995-2006.

74. Perathoner A, Weiss H, Santner W, Brandacher G, Laimer E, Höller E, et al. Vagal nerve dissection during pouch formation in laparoscopic Roux-Y-gastric bypass for technical simplification: Does it matter? Obes Surg 2009;19:412-7.

75. Wirth U, Kammal M, Doberauer J, Graw M, Schardey HM, Schopf S. Invisible scar endoscopic thyroid surgery by the dorsal approach: Importance of the spinal accessory nerve. Surg Radiol Anat 2011;33:703-11.

76. Tesei F, Poveda LM, Strali W, Tosi L, Magnani G, Farneti G. Unilateral laryngeal and hypoglossal paralysis (Tapia's syndrome) following rhinoplasty in general anaesthesia: Case report and review of the literature. Acta Otorhinolaryngol Ital 2006;26:219-21.

77. Shim JH, Park JW, Kwon BS, Ryu KH, Lee HJ, Lim WH, et al. Dysphagia in Ramsay Hunt's Syndrome - A case report. Ann Rehabil Med 2011;35:738-41

78. Gómez-Torres A, Medinilla Vallejo A, Abrante Jiménez A, Esteban Ortega F. Ramsay-Hunt syndrome presenting laryngeal paralysis. Acta Otorrinolaringol Esp 2013;64:72-4.

79. Van Den Bossche P, Van Den Bossche K, Vanpoucke H. Laryngeal zoster with multiple cranial nerve palsies. Eur Arch Otorhinolaryngol 2008;265:365-7.

80. Nishioka K, Fujishima K, Kobayashi H, Mizuno Y, Okuma Y. An extremely unusual presentation of varicella zoster viral infection of cranial nerves mimicking Garcin syndrome. Clin Neurol Neurosurg 2006;108:772-4.

81. Neuromuscular Disease Center. St. Louis, MO, USA: Washington University. Available from: http://www.neuromuscular.wustl.edu/. [Last accessed on $2015 \mathrm{Apr}]$.

82. Antoniades K, Giannouli TH, Vahtsevanos K. Hemifacial atrophy secondary to poliomyelitis. Int J Oral Maxillofac Surg 1997;26:215-6.

83. Hoshino S, Hayashi A, Ohkoshi N, Mizusawa H, Shoji S. A case of post-poliomyelitis muscular atrophy with cranial nerve signs and widespread muscular atrophy of the extremities. Rinsho Shinkeigaku 1997;37:407-9.

84. Toyoda H, Omata K, Fukai K, Akai K. A report on the pathology of type A botulism. Acta Pathol Jpn 1980;30:445-50.

85. Velázquez JM, Montero RG, Garrido JA, Tejerina AA. Lower cranial nerve involvement as the initial manifestation of Lyme borreliosis. Neurologia 1999;14:36-7.

86. Hirabayashi K, Morikawa N, Mori H, Miyake T, Suda K, Kondo T, et al. A 86-year-old woman with dementia, gait and speech disturbance, and right hemiparesis. No To Shinkei 1995;47:803-12.

87. Ebadi H, Fathi D. Unilateral hypoglossal nerve palsy: As the only presentation of tuberculosis. Acta Med Iran 2012;50:717-20.

88. Pawate S, Moses H, Sriram S. Presentations and outcomes of neurosarcoidosis: A study of 54 cases. QJM 2009;102:449-60. 
89. Hayashi T, Onodera J, Nagata T, Mochizuki H, Itoyama Y. A case of biopsy-proven sarcoid meningoencephalitis presented with hallucination, nominal aphasia and dementia. Rinsho Shinkeigaku 1995;35:1008-11.

90. Unal-Cevik I, Onal MZ, Odabasi Z, Tan E. IVIG- responsive multiple cranial neuropathy: A pharyngo-facial variant of Guillain-Barré syndrome. Acta Neurol Belg 2009;109:317-21.

91. Ochi M, Shinohara N, Kamogawa K, Okada Y, Nagai T, Taguchi K, et al. A case of Fisher syndrome with multiple cranial neuropathy and abnormal EEG findings. Nihon Ronen Igakkai Zasshi 2012;49:367-71.

92. Kawaguchi N, Sugeno N, Endo K, Miura E, Misu T, Nakashima I, et al. Recurrent hypogeusia in a patient with chronic inflammatory demyelinating polyradiculoneuropathy (CIDP). J Clin Neurosci 2012;19:604-5.

93. Hemmi S, Kutoku Y, Inoue K, MurakamiT, Sunada Y. Tongue fasciculations in chronic inflammatory demyelinating polyradiculoneuropathy. Muscle Nerve 2008;38:1341-3.

94. De Santi L, Annunziata P. Symptomatic cranial neuralgias in multiple sclerosis: Clinical features and treatment. Clin Neurol Neurosurg 2012;114:101-7.

95. Dall'ago P, D'Agord Schaan B, da Silva VO, Werner J, da Silva Soares PP, de Angelis $\mathrm{K}$, et al. Parasympathetic dysfunction is associated with baroreflex and chemoreflex impairment in streptozotocin-induced diabetes in rats. Auton Neurosci 2007;131:28-35.

96. Süfke S, Djonlagic H, Kibbel T. Impairment of cardiac autonomic nervous system and incidence of arrhythmias in severe hyperglycemia. Med Klin (Munich) 2010;105:858-70.

97. Yan B, Li L, Harden SW, Epstein PN, Wurster RD, Cheng ZJ. Diabetes induces neural degeneration in nucleus ambiguus (NA) and attenuates heart rate control in OVE26 mice. Exp Neurol 2009;220:34-43.

98. Pasricha PJ, Pehlivanov ND, Gomez G, Vittal H, Lurken MS, Farrugia G. Changes in the gastric enteric nervous system and muscle: A case report on two patients with diabetic gastroparesis. BMC Gastroenterol 2008 30;8:21.

99. Green R, Kara N, Cocks H. Vitamin B12 deficiency: An unusual cause of vocal fold palsy. J Laryngol Otol 2011;125:1309-11.

100. Beitzke M, Pfister P, Fortin J, Skrabal F. Autonomic dysfunction and hemodynamics in vitamin B12 deficiency. Auton Neurosci 2002;97:45-54.

101. Vucic S, Stein TD, Hedley-Whyte ET, Reddel SR, Tisch S, Kotschet K, et al. FOSMN syndrome: Novel insight into disease pathophysiology. Neurology 2012;79:73-9.

102. Cerimagic D, Ivkic G, Bilic E. Neuroanatomical basis of Sandifer's syndrome: A new vagal reflex? Med Hypotheses 2008;70:957-61.

103. Kurmann PT, Van Linthoudt D. Eagle syndrom: A rare cause of lateral neck pain. Praxis (Bern 1994) 2007;96:297-300.

104. Ferreira PC, Mendanha M, Frada T, Carvalho J, Silva A, Amarante J. Eagle syndrome. J Craniofac Surg 2014;25:e84-6.

105. Ertugrul EE, Cincik H, Cekin E, Dogru S, Güngör A. Type I Chiari malformation presenting with isolated unilateral hypoglossal nerve and vocal cord paralysis. Kulak Burun Bogaz Ihtis Derg 2008;18:118-20.

106. Ruiz-Juretschke F, García-Leal R, Garcia-Duque S, Panadero T, Aracil C. Glossopharyngeal neuralgia in the context of a Chiari type I malformation. J Clin Neurosci 2012;19:614-6.

107. Aguiar PH, Tella OI Jr, Pereira CU, Godinho F, Simm R. Chiari type I presenting as left glossopharyngeal neuralgia with cardiac syncope. Neurosurg Rev 2002;25:99-102.

108. Greenberg HS, Deck MD, Vikram B, Chu FC, Posner JB. Metastasis to the base of the skull: Clinical findings in 43 patients. Neurology 1981;31:530-7.

109. Mizuno J, Nakagawa H, Inoue T, Kondo S, Hara K, Hashizume Y. Signet-ring cell ependymoma with intratumoral hemorrhage in the medulla oblongata. J Clin Neurosci 2005;12:711-4.

110. Kumar R, Jain VK, Krisnani N. Choroid plexus papilloma of cerebellopontine angle with extension to foramen magnum. Neurol India 1999;47:71-3.

111. Sasahara A, Kawamata T, Kubo O, Okami N, Kawamura H, Hori T. Primary central nervous system malignant lymphoma originating from the cerebellum and extending along the lower cranial nerves. No Shinkei Geka 2000;28:879-83.

112. Cha ST, Jarrahy R, Mathiesen RA, Suh R, Shahinian HK. Cerebellopontine angle metastasis from papillary carcinoma of the thyroid: Case report and literature review. Surg Neurol 2000;54:320-6.
113. Sarrazin JL, Toulgoat F, Benoudiba F. The lower cranial nerves: IX, X, XI, XII. Diagn Interv Imaging 2013;94:1051-62.

114. Albanese A, Sturiale CL, D’Alessandris QG, Capone G, Maira G. Calcified extra-axial cavernoma involving lower cranial nerves: Technical case report. Neurosurgery 2009;64 3 Suppl: onsE135-6.

115. Mitsuyama T, Ide M, Hagiwara S, Tanaka N, Kawamura H, Aiba M. Adult choroid plexus papilloma of the posterior fossa: Extraventricular location. No Shinkei Geka 2005;33:825-9.

116. Leonetti JP, Anderson DE, Marzo SJ, Origitano TC, Shirazi M. Intracranial schwannomas of the lower cranial nerves. Otol Neurotol 2006;27:1142-5.

117. Johnson J, Morcos J, Elhammady M, Pao CL, Aziz-Sultan MA. Renal cell carcinoma metastasis to the cerebellopontine cistern: Intraoperative Onyx embolization via direct needle puncture. J Neurointerv Surg 2014;6:e41.

118. Grisold W, Briani C, Vass A. Malignant cell infiltration in the peripheral nervous system. Handb Clin Neurol 2013;115:685-712.

119. Ishikawa T, Shimazaki H, Morita M, Sawada M, Takiyama Y, Nakano I, et al. An autopsy case of origin-unidentified meningeal carcinomatosis presenting with monoradiculopathy multiplex in the lower extremities. Rinsho Shinkeigaku 2005;45:32-7.

120. Patsalides AD, Atac G, Hedge U, Janik J, Grant N, Jaffe ES, et al. Lymphomatoid granulomatosis: Abnormalities of the brain at MR imaging. Radiology 2005;237:265-73.

121. Villatoro R, Romero C, Rueda A. Collet-Sicard syndrome as an initial presentation of prostate cancer: A case report. J Med Case Rep 2011;5:315.

122. Bulsara KR, Sameshima T, Friedman AH, Fukushima T. Microsurgical management of 53 jugular foramen schwannomas: Lessons learned incorporated into a modified grading system. J Neurosurg 2008;109:794-803

123. Leonetti JP, Shirazi MA, Marzo S, Anderson D. Neuroendocrine carcinoma of the jugular foramen. Ear Nose Throat J 2008;87:86, 88-91.

124. Ramina R, Maniglia JJ, Fernandes YB, Paschoal JR, Pfeilsticker LN, Coelho Neto M. Tumors of the jugular foramen: Diagnosis and management. Neurosurgery 2005;57 1 Suppl: 59-68.

125. Ichimura S, Yoshida K, Kawase T. Surgical approach for hypoglossal schwannomas to prevent deformity of the atlanto-occipital joint. Acta Neurochir (Wien) 2009;151:575-9.

126. Gibber MJ, Zevallos JP, Urken ML. Enucleation of vagal nerve schwannoma using intraoperative nerve monitoring. Laryngoscope 2012;122:790-2.

127. Dhull AK, Kaushal V, Atri R, Dhankhar R, Kataria SP. Giant neurilemmoma of the vagus nerve: A case report and review of literature. J Indian Med Assoc 2012;110:926-8.

128. Shaia WT, Bojrab DI, Babu S, Pieper DR. Lipomatous hemangiopericytoma of the skull base and parapharyngeal space. Otol Neurotol 2006;27:560-3.

129. Sheehan JP, Tanaka S, Link MJ, Pollock BE, Kondziolka D, Mathieu D, et al. Gamma Knife surgery for the management of glomus tumors: A multicenter study. J Neurosurg 2012;117:246-54.

130. Diaz RJ, Guduk M, Romagnuolo R, Smith CA, Northcott P, Shih D, et al. High-resolution whole-genome analysis of skull base chordomas implicates FHIT loss in chordoma pathogenesis. Neoplasia 2012;14:788-98.

131. Onrot J, Wiley RG, Fogo A, Biaggioni I, Robertson D, Hollister AS, Neck tumour with syncope due to paroxysmal sympathetic withdrawal. J Neurol Neurosurg Psychiatry 1987;50:1063-6.

132. Rothstein SG, Jacobs JB, Reede DL. Carotid sinus hypersensitivity secondary to parapharyngeal space carcinoma. Head Neck Surg 1987;9:332-5.

133. Reyes N, Terrón C, Martínez E, Zabala JA, Larrondo J. Progressive cranial neuropathy due to perineural spread of a facial squamous cell carcinoma. Neurologia 2003;18:112-5.

134. Gartrell BC, Hansen MR, Gantz BJ, Gluth MB, Mowry SE, Aagaard-Kienitz BL, et al. Facial and lower cranial neuropathies after preoperative embolization of jugular foramen lesions with ethylene vinyl alcohol. Otol Neurotol 2012;33:1270-5.

How to cite this article: Finsterer J, Grisold W. Disorders of the lower cranial nerves. J Neurosci Rural Pract 2015;6:377-91.

Source of Support: Nil. Conflict of Interest: None declared. 